\title{
EXPLORING THE CHEMISTRY OF MARINE OPISTHOBRANCHS: RECENT RESULTS
}

\author{
Margherita Gavagnin \\ Istituto di Chimica Biomolecolare (ICB), Consiglio Nazionale delle Ricerche, \\ Via Campi Flegrei, 34, 80078 Pozzuoli (Na), Italy \\ e-mail: margherita.gavagnin@icb.cnrit,phone: +39 0818675094,fax: +390818041770
}

\begin{abstract}
The current communication is an extended abstract of the presentation delivered on the joint Moldo-Italian seminar "New frontiers in natural product chemistry", held in the Institute of Chemistry, Academy of Sciences of Moldova on $30^{\text {th }}$ September. An overview of the recent studies conducted by our group on opisthobranch molluscs from distinct geographical areas is briefly presented.
\end{abstract}

\section{Introduction}

Marine opisthobranch molluscs are apparently unprotected by the physical constraint of a shell which is either reduced or completely absent in the adults. Their survival is based on a series of defensive strategies, which include the use of deterrent or toxic molecules. Opisthobranchs obtain their chemical "weapons" by either bio-accumulation of selected metabolites from their dietary sources, bio-transformation of dietary compounds, or de novo bio-synthesis [1]. Thus they represent a remarkable source of bioactive molecules that have been selected in nature to play fundamental roles for the survival of the species that contain them. This reveals an extraordinary library of compounds that could be considered excellent drug candidates. Among others, a remarkable example is represented by jorumycin (1), the defence allomone of the opisthobranch Jorunna funebris, which was isolated some years ago by our group from the mantle and the mucus of the mollusc [2]. The synthetic analogue of jorumycin, Zalypsis ${ }^{\circledR}$ (PharmaMar), is now in phase II clinical trial for the treatment of endometrial and cervical tumours [3]. This communication presents an overview of our recent results obtained studying opisthobranchs collected in different sites around the world, in the frame of international collaboration programs.

The chemical investigation of a Chinese population of J. funebris [4] has led to the isolation of a series of alkaloids analogues of jorumycin (i.e. 2-4), which were differently distributed in the distinct parts of the animal suggesting possible different biological properties. In the internal organs a plethora of isoquinoline-quinone alkaloids probably derived from the oxidative degradation of renieramycins were also found [4].

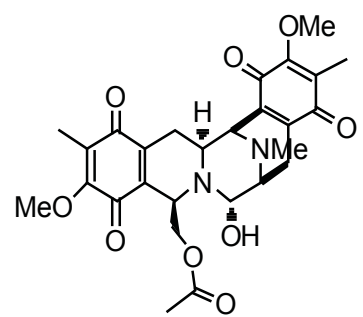

jorumycin (1)

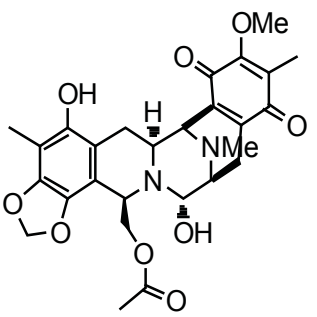

2

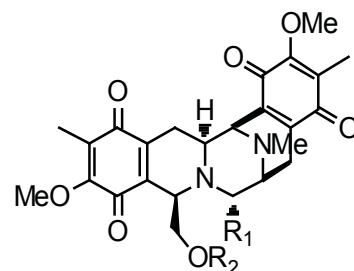

3: $\mathrm{R}_{1}=\mathrm{CH}_{2} \mathrm{COCH}_{3} ; \mathrm{R}_{2}=\mathrm{H}$

4: $\mathrm{R}_{1}=\mathrm{CH}_{2} \mathrm{COCH}_{3} ; \mathrm{R}_{2}=\mathrm{COCH}_{3}$

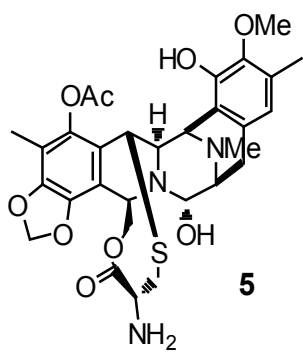

5

A new member of the ecteinascidin family, compound $\mathbf{5}$, structurally related to jorumycin and renieramycin series, has been isolated from the external part of some specimens of the eolidacean nudibranch Phidiana militaris, collected in South China Sea [4]. In addition, the extract of the mollusc contained two other new and extremely interesting molecules: phidianidine A (6) and B (7) exhibiting an uncommon carbon skeleton with a 1,2,4-oxadiazole system never reported from marine natural products [5]. This structural moiety has been found only in quisqualic acid isolated from the fruits of a tropical plant. Even though the 1,2,4-oxadiazole system is so rare, there is a wide interest in the synthesis of compounds containing this scaffold due to the broad spectrum of biological properties. The cytotoxicity of phidianidines has been evaluated in terms of cell grow inhibition and the results are very interesting. Both compounds have shown high cytotoxicity against various tumour and non-tumour mammalian cell lines at nanomolar concentration [5]. The specificity towards some cell types relative to others (strongly active against C6 and HeLa cancer cell lines) suggests the existence of specific interactions with biological targets.

Remaining in the eolidacean group, the chemical investigation of two different Spurilla species from Argentina and Italy has revealed a different composition of the terpene content of the two molluscs. A new molecule, diterpene $\mathbf{8}$, 
has been characterized in this study [4]. Very interestingly, bursatellin $\mathbf{9}$, structurally related to antibiotic chloramphenicol and previously reported from the anaspidean Bursatella, has been found in both species.<smiles>[R]c1ccc2[nH]cc(Cc3nc(NCCCCNC(=N)N)no3)c2c1</smiles>

phidianidine $\mathrm{A}(\mathbf{6}): \mathrm{R}=\mathrm{Br}$ phidianidine $B(7): R=H$<smiles>CC(C)=CCC1C(C)=CCC(O)C1(C)CCC(C)=CCO</smiles>

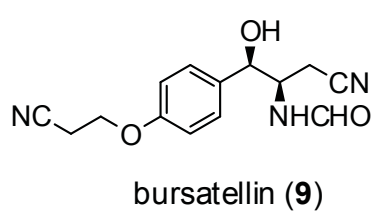<smiles>CCCCCCCCCCCCCCCOCC(C)OC(C)=O</smiles><smiles>Cc1ccc2c(C)c(C)ccc2c1C</smiles>

ionenol (11)

The chemistry of the nudibranch Actinocyclus papillatus from South China Sea is very interesting [6]. The main metabolite of the mantle extract is the novel molecule actisonitrile (10). This compound is an ether lipid with a glyceryllike moiety in which the secondary hydroxyl function is replaced by an isocyanide group. Another uncommon compound, methyl- $\beta$-ionene alcohol (11) has been also found in both mucus and mantle. The two molecules were tested for the cytotoxicity against a series of tumour and non-tumour cell lines. Actisonitrile revealed a moderate activity suggesting to further investigate the pharmacological potential. In this light, it was necessary to complete the structure determination of actisonitrile (10) with regards to the assignment of the absolute configuration of the single chiral centre.

The stereospecific synthesis of both enantiomers of actisonitrile was planned with the aim at comparing the optical properties of synthetic products with natural 10 [6]. In Scheme 1 are reported all steps to construct one of the two enantiomers. The enantiomer with the opposite configuration has been prepared in the same way starting from the same precursor with the opposite chirality. The comparison of the optical rotation values and the circular dichroism profiles of synthetic compounds with those of natural product led us to establish that actisonitrile has the $R$ configuration.

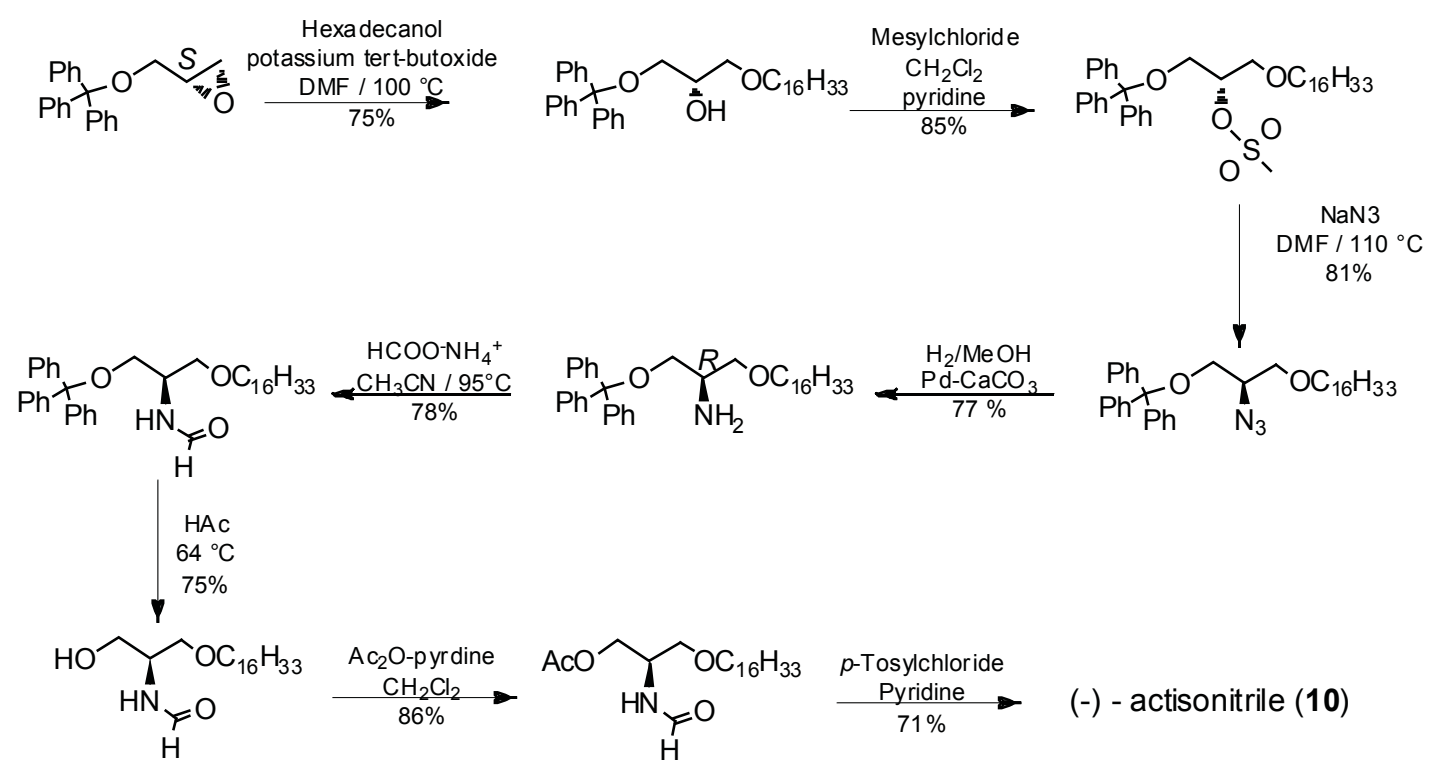

Scheme 1

The family Chromodorididae is the most studied group of nudibranchs from a chemical point of view. Most species belonging to this family contain dietary terpenes which are generally accumulated in the border of the mantle or in mantle dermal formations. Some selected species collected in South China Sea have been analyzed [4]. Chromodoris reticulata was found to contain aplyroseol-2 (12) as main metabolite along with other two known related diterpenes $(\mathbf{1 3}, \mathbf{1 4})$. All three diterpenes have been reported to be cytotoxic being aplyroseol-2 the most active [7]. Aplyroseol-2 has been demonstrated to be also unpalatable for the marine shrimp Palamon elegans [4]. This very nice and simple 
assay has been performed in our lab [8]. The use of colored pellets allows to observe easily if the food treated with the compound to be tested is accepted or rejected by a generalist predator. Similar diterpene components including aplyroseol-2 (12) have been isolated from Chromodoris sinensis [4]. In the mantle border of the animal, we were able to detect by ${ }^{1} \mathrm{H}-\mathrm{NMR}$ analysis the unstable compound $\mathbf{1 5}$ exhibiting two dialdehyde groups that is the precursor of $\mathbf{1 2}$. This molecule is highly reactive and is rapidly converted into the corresponding lactone-hemiacetal derivative $\mathbf{1 2}$. The comparison of the proton spectra of the same sample before and after the filtration on silica-gel clearly demonstrates the rapid transformation [4]. Known degraded spongiane diterpenes (i.e. 16,17) have been isolated from Chromodoris geometrica [4]. A correspondence between the ecological and the pharmacological activity could be observed also in this case. Particularly interesting are the pharmacological properties of macfarlandin-E (16) and norrisolide (17) that exhibit a potent and unique Golgi-modifying activity [9]. Analogously with other Glossodoris species, the chemistry of Glossodoris cincta is characterized by the presence of sesterterpenes. Heteronemin (18) is the main component of the terpene pattern of the nudibranch and is also the most active showing several different biological properties. In particular, it has been recently reported that heteronemin is a potent and promising inhibitor of TNF $\alpha$-induced NF-kB activation [10].

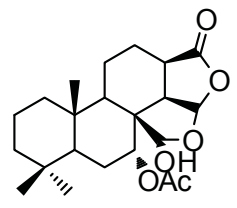

aplyroseol 2 (12)

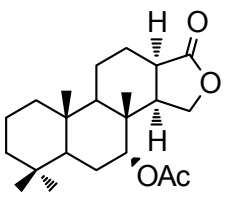

13

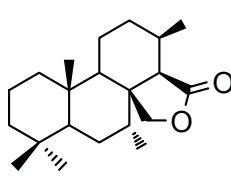

14

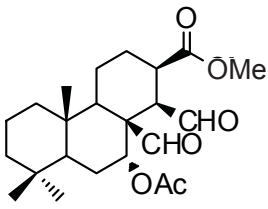

15

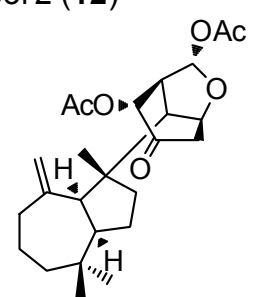

macfarlandin-E (16)<smiles>C=C1OC2OC(=O)CC2C1C1CCC2(C)CCCCC12C</smiles>

norrisolide (17)

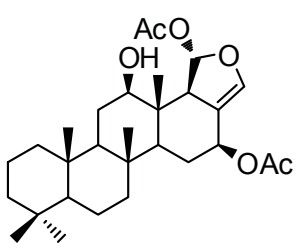

heteronemin (18)

The chemistry of the nudibranch Dermatobranchus ornatus from South China Sea has been found to be characterized by some known diterpenes with eunicellin skeleton (i.e. 19). These molecules are sequestered from a gorgonian of genus Muricella and accumulated in the mantle of the animal [11]. Cytotoxic properties have been reported in the literature for some of these compounds [12]. Structurally related molecules, named tritoniopsins $(\mathbf{2 0 , 2 1 )}$, characterized the metabolite pattern of a Chinese population of Tritoniopsis elegans which was found associated to the soft coral Cladiella krempfi [13]. All isolated compounds, which were also detected in the prey, were evaluated for the cytotoxic activity. Tritoniopsin B (21) was the most active.

The secondary metabolite pattern of Mediterranean Discodoris atromaculata is dominated by a series of longchain polyacetylenes, named fulvynes (i.e. 22) all deriving from the sponge Haliclona fulva on which the animal feeds [4]. The biological properties of these molecules have not yet been investigated. However, it is interesting to note that they are structurally related to petrocortyne A, which is a potent modulator of the transcription factor NF-kB [14].

The chemistry of the nudibranch Tambja ceutae collected at Azores along with the bryozoan Bugula dentata was found to be characterized by a series of 4-methoxy-pyrrolic alkaloids belonging to the tambjamine family [15]. Tambjamines are reported to intercalate DNA and facilitate single-strand DNA oxidative cleavage. The new member we isolated (tambjamine $\mathrm{K}, \mathbf{2 3}$ ) has displayed a significant antiproliferative activity against different tumor and non-tumor cell lines.

The chemical studies on a population of circumtropical anaspidean Syphonota geographica, collected along the Greek coasts, led us to discover very interesting bioactive natural products [16-19]. The skin metabolites, aplykurodinones (i.e. 24), are degraded sterols that are typical of different species of the family Aplysiidae from distinct geographical areas [16]. 


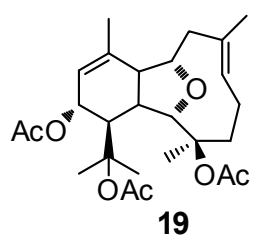

19

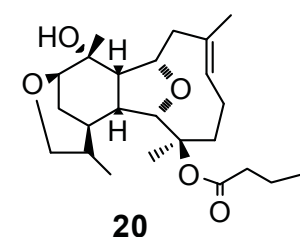

20

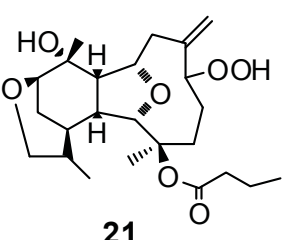

21

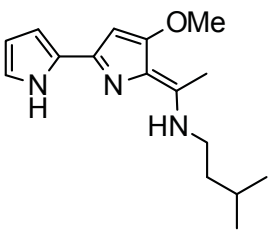

tambjamine $\mathrm{K}(\mathbf{2 3})$

The metabolite pattern of the inner organs was found to be dominated by the presence of syphonoside (25), a macrocycle with a unique structure, that inhibits high-density induced apoptosis [17]. This bioactive compound is sequestered from the sea-grass Halophila stipulacea, prey of the mollusc. Further studies on both the mollusc and the sea-grass have resulted into the finding of a series of novel minor syphonoside-related compounds (i.e. 26) [18] as well as of two very rare malonyl flavones (i.e. 27) [19].<smiles>CC(C)=CCC[C@H](C)[C@H]1CC(=O)[C@H]2CC(=O)O[C@@H]2CCC1(C)C</smiles>

24

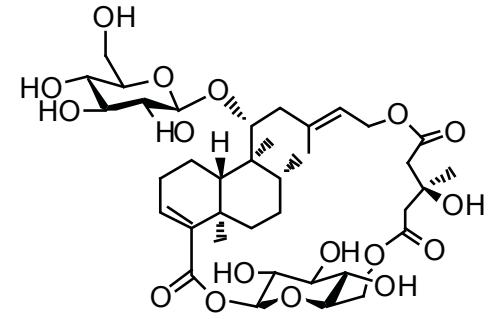

syphonoside (25)

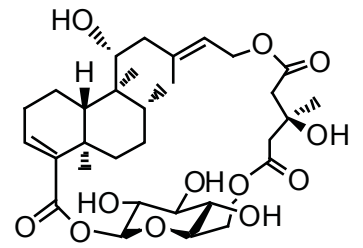

26

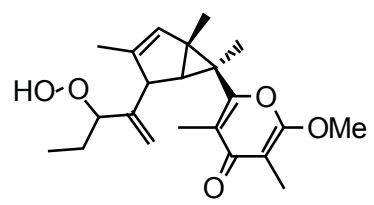

phototridachiapyrone J (29)<smiles>CC/C=C(\C)c1cc(OC)c(C)c(=O)o1</smiles>

28

Finally, a few examples of chemicals isolated from sacoglossans should be mentioned. The Azorean Aplysiopsis formosa was found to contain aplysiopsenes (i.e. 28) [20]. These compounds belong to the sacoglossan polypropionate family and are the smallest members to date isolated. Polypropionates interact with the light by trapping oxygen and therefore protecting the molluscs from sunlight damage. So it has been suggested a possible use as sunscreen in the solar creams [21]. The chemical study on Elysia patagonica from Argentina has led to the finding of a new member of elysioidean polypropionates, tridachiapyrone J (29) [4]. This molecule is probably formed by a photochemical conversion of a suitable precursor containing the reactive conjugated diene system [21]. However, the main secondary metabolite of Elysia patagonica has resulted to be the osmolyte proline betaine [4]. Our studies have demonstrated that this compound, which is accumulated in the mollusc, derives from the diet, the alga Bryopsis plumosa. Comparison of the proton spectrum of proline betaine purified from the mollusc extract with that of crude extract of the alga clearly showed the presence of this compound in the alga. In addition, we have also proven that Mediterranean sacoglossans Ercolanea funerea, Caliphylla mediterranea and Placida dendritica all feeding on Bryopsis plumosa, analogously with Elysia patagonica, are able to sequester proline betaine from the diet and accumulate this molecule in the defensive mucous secretion.

Conclusions. The examples presented here clearly indicate that marine opisthobranch molluscs are a remarkable source of natural products with a high pharmacological potential. The large chemical diversity observed in these organisms reflects their ability of colonizing several different ecological niches and establishing trophic relationships with organisms of different phyla, from which they select bioactive molecules. 
Acknowledments. Academy of Sciences (Moldova) and CNR (Italy) are acknowledged for financial support (bilateral project Kulcitki/Gavagnin "Novel approaches for the synthesis of optically active cannabinoids with relevant biological activity and therapeutical potential").

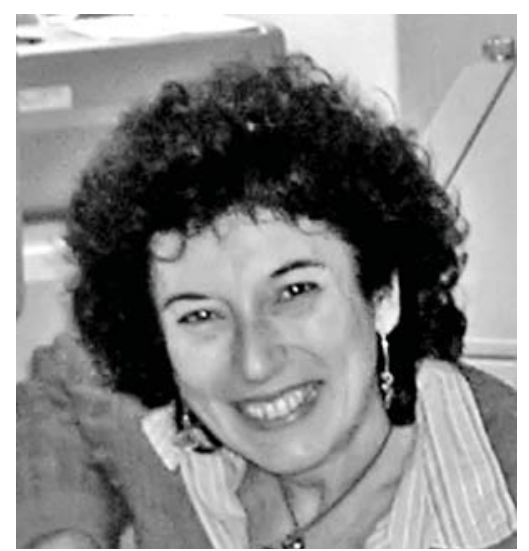

Margherita Gavagnin was born in Naples in 1959. She received her doctoral degree in organic Chemistry in 1983 from Naples University. She spent one postdoctoral year at the Institute of Organic Chemistry of Naples, working in the field of marine natural products. In 1985 she moved, as researcher of the Italian National Council of Research, to the Institute of Chemistry of Molecules of Biological Interest, now Institute of Biomolecular Chemistry, where she has been First Researcher and subsequently Research Director. She has been in charge of research project management in CNR and responsible of several national research projects and bilateral co-operation programmes. She has been member of the Scientific Council of ICMIB and member of ICB Committee. During these years, the scientific activity has been mainly oriented to the chemical characterization of bioactive marine natural products. Most studies have been focused to opisthobranch molluscs, which represent extraordinary models to select leadcompounds for drug development. She is author of more than 130 papers.

\section{References}

[1]. G. Cimino, A. Fontana, M. Gavagnin Curr. Org. Chem., 1999, 3, 327-372; G. Cimino, M.L. Ciavatta, A. Fontana, M. Gavagnin. In C. Tringali (Ed.) Bioactive compounds from natural sources Taylor \& Francis, London, 2001, pp.579-637; G. Cimino, M. Gavagnin (Eds) Molluscs. From Chemo-ecological Study to Biotechnological Application. Vol. 43, Springer 2006; G. Cimino, A. Fontana, A. Cutignano, M. Gavagnin Phytochem. Rev., 2004, 3, 285-307.

[2]. A. Fontana, P. Cavaliere, S. Wahidullah, C.G. Naik, G. Cimino Tetrahedron, 2000, 56, 7305-7308.

[3]. a) G. Cimino, A. Fontana, S. Wahidulla, C. G. Naik, D. G. Gravalos. WO 2000-GB3489-2000/09/11. PCT Int. Appl. 2001:1-9. b) EP20000958872. July 2003. c) WO/2007/052076. May 2007.

[4]. Unpublished results.

[5]. M. Carbone, Y. Li, C. Irace, E. Mollo, F. Castelluccio, A. Di Pascale, G. Cimino, R. Santamaria, Y.-W. Guo, M. Gavagnin, Org. Letters, 2011, 13, 2516-2519.

[6]. E. Manzo, M. Carbone, E. Mollo, C. Irace, A. Di Pascale, Y. Li, M. L. Ciavatta, G. Cimino, Y.-W. Guo, M. Gavagnin, Org. Letters, 2011, 13, 1897-1899.

[7]. T. Miyamoto, K. Sakamoto, K. Arao, T. Komori, R. Higuchi, T. Sasaki Tetrahedron 1996, 52, 8187-8198.

[8]. E. Mollo, M. Gavagnin, M. Carbone, F. Castelluccio, F. Pozone, V. Roussis, J. Templado, M. T. Ghiselin, G. Cimino, PNAS, 2008, 105, 4582-4586.

[9]. T.P. Brady, E.K. Wallace, S.H. Kim, G. Guizzunti, V. Malhotra, E.A. Theodorakis Bioorg. Med. Chem. Lett., 2004, 14, 5035-5039.

[10]. M. Schumacher, C. Cerella, S. Eifes, S. Chateauvieux, F. Morceau, M. Jaspars, M. Dicato, M. Diederich, Biochem. Pharmacology, 2010, 79, 610-622.

[11]. W. Zhang, M. Gavagnin, Y.-W. Guo, E. Mollo, G. Cimino, Chin. J. Org. Chem., 2006, 26, 1667-1672.

[12]. M. Ochi, K. Yamada, K. Shirase, H. Kotsuki Heterocycles 1991, 32, 19-21; N. Fusetani, H. Nagata, H. Hirota, T. Tsuyuki Tetrahedron Lett. 1989, 30, 7079-7082.

[13]. M.L. Ciavatta, E. Manzo, E. Mollo, C. A. Mattia, C. Tedesco, C. Irace, Y.-W. Guo, G. Cimino, M. Gavagnin, J. Nat. Prod., 2011, 74, 1902-1907.

[14]. F. Folmer, M. Jaspars, M. Dicato, M. Diederich, Biochem. Pharmacology, 2008, 75, 603-617.

[15]. M. Carbone, C. Irace, F. Costagliola, F. Castelluccio, G. Villani, G. Calado, V. Padula, G. Cimino, J. L. Cervera, R. Santamaria, M. Gavagnin, Bioorg. Med. Chem. Lett., 2010, 20, 2668-2670.

[16]. M. Gavagnin, M. Carbone, M. Nappo, E. Mollo, V. Roussis, G. Cimino, Tetrahedron, 2005, 61, 617-621.

[17]. M. Gavagnin, M. Carbone, P. Amodeo, E. Mollo, R. M. Vitale, V. Roussis, G. Cimino, J. Org. Chem., 2007, 72, 5625-5630.

[18]. M. Carbone, M. Gavagnin, E. Mollo, M. Bidello, V. Roussis, G. Cimino, Tetrahedron, 2008, 64, 191-196.

[19]. F. . Bitam, M.L. Ciavatta, M. Carbone, E. Manzo, E. Mollo and M. Gavagnin, Biochem. System. Ecol., 2010, 38, 686-690.

[20]. M.L. Ciavatta, E. Manzo, G. Nuzzo, G. Villani, J. L. Cervera, G. Cimino, M. Gavagnin, Tetrahedron Lett., 2009, 50, 527-529.

[21]. C. Ireland, P.J. Scheuer, Science. 1979, 205, 922- 923. 